\title{
Design and Implementation of a College English Listening Learning System Based on Android Platform
}

\author{
https://doi.org/10.3991/ijet.v13i07.8779 \\ Hongbo Huang \\ University of Science and Technology Liaoning, Liaoning Provinc, China \\ hbhuang1293@ $21 \mathrm{cn} . \mathrm{com}$
}

\begin{abstract}
To create a good English listening learning environment for college students, based on the Android platform and learning from mobile learning theory and language learning theory, Android software platform was applied to design and develop a learning system for college students' English listening. The system could provide a relatively complete listening learning system according to the listening cognition rule, increase the intelligence test, strengthen the listening training and feedback mechanism, help improve the listening level step by step, and improve the input and output process of listening learning. The practice showed that the system could effectively improve the learning effect of college students' English listening mobile learning.
\end{abstract}

Keywords-Android platform; college English; listening learning system

\section{Introduction}

In recent years, the mobile communication devices are applied in English learning, especially for training listening skills, which receives extensive attention from English learners, teachers, researchers and businesses in the field. With the continuous development of the mobile phone market, the popularity of smart phones has made it an ideal learning platform.

At present, the mobile English learning system based on smart phone is quite diverse, with different editions and rich contents. However, a good software needs to pay, so many learners will stop, causing embarrassment that resources cannot be used. These products lack theoretical support and cannot meet learners' cognitive rules. Some products offer limited resources that cannot meet the needs of college students' English learning. From the content point of view, the vast majority of the products only play the role of the dictionary tool. The software that uses word learning as the theme is the majority, and the function is more and more advanced. It provides a good environment for the learners, and the little software is based on comprehensive services such as word reading, which has expanded the students' knowledge reserve, while only a few software provides the training service of listening and speaking. There are two reasons after the analysis: first, the ability of listening and speaking is more abstract, and its input and output structure is more complex than the word learning. It only provides the material to listen to but cannot achieve the ideal effect. Se- 
cond, the training of listening and speaking is often not paid attention to, and the market demand is not much more than vocabulary learning.

This paper tries to design and develop a college English listening learning system based on smart phones. The purpose is to create a learning environment that can learn anywhere and anytime for college English listening, to increase the opportunities for students to contact English listening, and to improve their English listening ability.

\section{Literature review}

In recent years, domestic and foreign has also made great progress in technology for developing mobile platform learning. In 2010, Chappel and other scholars proposed a mobile virtual campus platform, which could download the teaching materials to mobile phones in a variety of ways to realize mobile university [1]. In order to meet the needs of cross platform and multi terminal, some scholars, like Zheng, used mobile Internet, HTML5, response Web design technology and MVC technology architecture [2]. The experimental results show that the method can work effectively, and it can be widely applied in teaching system. Zhang carried out the framework design of mobile English teaching system in higher vocational colleges based on Android platform [3]. In terms of music curriculum, Android also has room to play. Through research, Tong found that Android system optimization teaching could improve students' performance and comprehensive quality level of music curriculum [4]. Dewitt and some other scholars designed a learning system based on Android, which was suitable for short-term learning, open learning system and enhanced level learning [5]. Pharmacopoeia is a national guideline for drug use. Its content is rich, but its structure is complex. The traditional resource based pharmacopoeia learning system has limited time and place, so learning is inconvenient. Liao and so on developed an intelligent learning system based on the Android system, which was learner - centered, self centered and interactive - oriented [6]. Ally \& Prietoblázquez pointed out that the establishment of mobile English will have a greater development space, and the advantage of establishing a college English learning system on mobile devices will certainly occupy a place in the future English education practice [7]. In addition, with the implementation of big data and cloud technology, handheld learning software has been launched in recent years, and the number of users is also increasing.

With the rapid development of mobile Internet, the increasing popularity of smart phones and the continuous appeal of educational innovation, the way of learning English listening learning needs to be combined with the latest technology and the way of living and learning. It will also be of great significance to develop a college English listening learning system based on the Android platform. In this paper, Android software platform is applied to design and develop a learning system for college students' English listening. The system can provide a relatively complete listening learning system according to the listening cognition rule, increase the intelligence test, strengthen the listening training and feedback mechanism, and help improve the listening level step by step. 


\section{Method}

A developed Android program is mainly composed of four parts of Activity, Service, Broadcast Recdver, and Content Provider. Activity is used for performance, Service is equivalent to Activity running in the background, Broadcast Reciever is used to receive broadcasting, and Content Provider supports storage and reading of data in multiple applications. These four parts are not indispensable. Each Android application, but these four parts are not indispensable. Each Android application has a XML configuration file named Android Mainfest, which is configured for program components, component functions and necessary conditions when the program is used.

Because the Android system itself is based on Limix system, its application integrated development environment is also a platform for cross platform and cross operation system. At present, the most mainstream is the development environment under the Windows system. Therefore, this paper also chooses Android application integration development environment under Windows system to do research and exploration.

In general, building the Android program development environment under Windows requires completing the following tasks one by one: setting up the Java language running environment in Windows and installing JDK; installing Eclipse development software and Android SDK; installing Android development plug-in ADT; creating Android AVD.

\section{Result}

\subsection{Client architecture design of college English listening learning based on Android platform}

MVC (Modd-View-Controller) is a popular software design mode at present. In Android application development, MVC can well separate interface display from data logic processing. The client application framework in this article uses the MVC mode, which includes three core components: the data model, the view, and the controller, as shown in Figure 1. Model is used to define data patterns and access to data. The data to display in View and the methods to be invoked in Controller are placed in Modle. When parsing XML data streams, specific object instances are generated and stored in the directory of the SRC of the project; View is a user interface to provide data and interactive components for users. It implements the transformation between the internal form of the information and the acceptable form of the user. It is generally described with XML and placed under the layout folder; Controller is used to call View and Modle to complete the user requirements. After receiving the user's input, it calls the Modle to process the user's requests and then determines how to use View to display the data returned by the Modle. In general, Activity is used as a controller of Android, which is responsible for connecting View and Model and controlling the flow of application. 

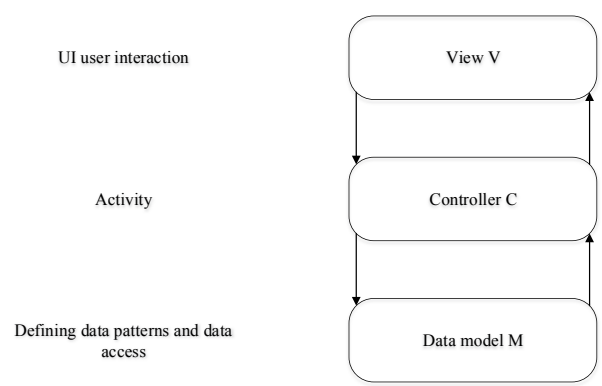

Fig. 1. MVC Model

\subsection{Client function design}

In order to clarify the specific functions of the client, we will use the use case diagram to show it. The system is shown in Figure 2.

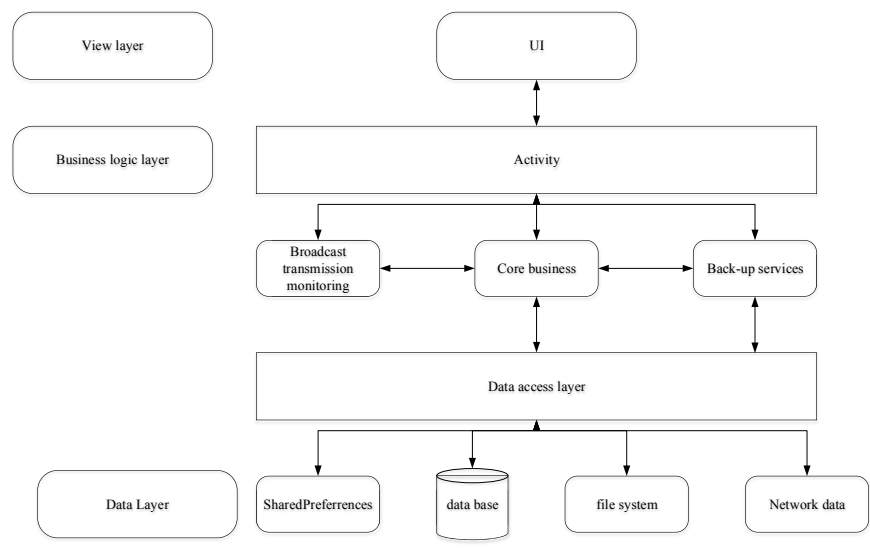

Fig. 2. System Use Case

Learners can do local learning and online learning in the system. In local learning, learners can learn lessons, supplement knowledge, test ability and record learning notes. The main course is college English teaching materials. Knowledge supplement mainly involves phonetics, grammar and listening skills and it is the knowledge treasure of the learners. The ability test includes the 46 level tests and the intelligent test introduced by the system. The intelligent test is based on the current level of the learners to carry out random question choosing. The learner's weakness is found and the learner is mastered by the reciprocating cycle to enter a higher stage; learning feedback is the true expression of the learner's learning situation, including the learning length, performance and learning suggestions. Online learning is mainly for learners to download resources and exchange of forums. Learners can get a lot of extracurricular listening resources. At the same time, learners can communicate with the outside world, share their feelings and expand their knowledge through forum. The sys- 
tem should also provide learners with listening resources, intelligent questions, learning feedback and Internet services.

The mobile learning system client is implemented by Java language coding, and Android2.2 version SDK is selected as the development environment. According to the purpose of this paper, the system includes word memory, knowledge lecture hall, listening resources, exam experts, learning community, and my learning functions, as shown in Figure 3. The content corresponds to different Activity. After the client program starts, the system first of all runs the welcome interface, then enters the home page and starts the whole program flow.

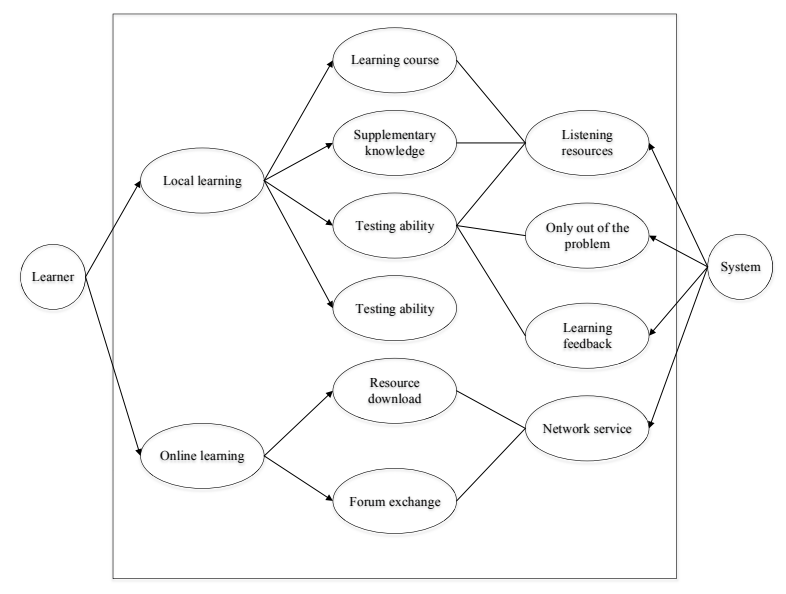

Fig. 3. The Functional Modules of College English Listening Clients

\subsection{Word memory}

Word memory is the basis of listening comprehension. Listening and reading words can allow students to follow the audio to read the words and strengthen pronunciation and spelling; self-test can achieve the memory and consolidation of words, which is divided into translation from English to Chinese and Chinese to English two aspects. For the words on the screen, the learners need to choose the right option, and then the answer will soon appear below the screen, so that it can be corrected in time, so as to consolidate the degree of memorization of words, and lay a foundation for improving learners' listening learning effect.

When entering the word memory module Word Activity, according to the unit content that the user chooses to learn, load the corresponding audio files and text data on the SD card, such as mp3Path=SDPATH+ "//english//wordclassroom// " +index+" //1.mp3", and then decompose the text play time and text content in the Ire text file by using the readLrc function. The time and text content is parsed, such as readLrc (SDPATH+ "//eng]ish//wordclassroom//" +index+ "//1.Jrc"), stored in lrc map. When the user clicks the play button to play the audio, and opens a thread newThread(newmnable()).start() that updates the text in the background. As a result, 
when the audio is played forward, the thread will start updating text every $100 \mathrm{~ms}$, and the text that should be displayed at this time is displayed by querying lrc_map.

This article uses Radio Button as the display control of the problem options, and Radio Group as a display control of a problem, so that each Radio Group nests 3 Radio Button. It also means three options in one question, and each Radio Button displays the corresponding option answers.

The user selects a Radio Button, which means that the user chooses the corresponding answer of Radio Button. Then, each Radio Group is bound to the click event, and when the user clicks on the nested Radio Button, the click event function will record the answer representative by the Radio Button as the answer to the title of the Radio Group, and then monitor what the user does by the set On Checked Change. In addition, it displays if it is the right answer in accordance with the choice. If the answer is correct, it will display correct. If it is wrong, it will display wrong.

\subsection{Knowledge lecture hall}

Knowledge lecture hall provides learners with essential basic knowledge in listening learning, including speech learning, grammar supplement and listening skills. The knowledge facilitates learners to browse at any time, and lay the foundation for listening practice.

The knowledge lecture hall is made up of pure text. It is mainly to encapsulate several functions of the knowledge lecture hall into the List View, and in response to the click events of each part, enter the corresponding function Activity, and then display the specific knowledge content to the Text View. Because the text is long and the screen is not fully displayed, it is necessary to drag the text, so we can use the Scroll View to realize the display with the control over the screen. Scroll View is a hierarchical layout container for users to scroll. We put Text View in a ScroHView, fix the width (layout width) and high (layout height) of the Scroll View, and set the layout_width of Text View as filljparent, layout_height as wrap_content and attribute of android:orientation as vertical. In this way, the effect of text slipping can be achieved. When the learner clicks on the knowledge lecture hall and selects the listening skill to enter, it gets the relevant text information and can read the part of the text beyond the screen by slippery way.

\subsection{Listening classroom}

Listening classroom is the main source of learners' knowledge expansion, including resources in class and extracurricular resources. In the listening classroom, the audio and text contents are placed in the specified directory in advance. The new thread will constantly update each sentence and audio corresponding to the text content appearing above the screen, and use Strollview to lay out below the screen, providing a Chinese translation of the whole article.

Extracurricular resources can allow learners to gain more learning content. The system recommends popular learning websites, such as "American voice" and "twenty-first Century English", which enable learners to acquire social dynamics from the 
perspective of English, enlarge vocabulary and enhance language ability in entertainment learning. The specific practice is to define the Web View component in the layout XML file, and Web View is a component under the android.webkit package, which can be used to display the web page and add the network access rights "android.permission.INTERNET" through the Android Manifest.xml. If not, the "Web page not available" error will occur. Then we use load function to load web pages and complete corresponding links.

\subsection{Examination expert}

The examination expert is an important ability assessment module of the system. It includes two types of old exam test and intelligent test. The old exam test mainly summarizes the years of hearing exams, and students complete answer by clicking selection and input. The results are immediately known, and can also check the correct rate for feedback.

Intelligent test is the focus of this system design, so that it can provide students with a training mechanism to gradually improve their ability. This intelligent test system is combined into a set of questions which are different in difficulty by random test. The students begin to test from the simplest level. The system filters the questions that the learners answer correctly according to the students' answers. When we choose the questions next time, the questions that we answer wrongly will be chosen again and new questions will be added. It is repeated until the learners meet the requirements and then we can enter the next stage of testing. Through a layer of test and feedback, on the one hand, the learner can repeatedly consolidate the wrong questions; on the other hand, it can also stimulate the motivation and enthusiasm of the learners to continue to study.

The learners enter the intelligent test module and divide the four and six level evaluation areas, each including the Easy, Moderate, and Hard three levels and different difficulties are set, respectively. Learners begin to test from the lowest level and click entering. The system selects subjects that are difficult to choose for learners to test. After finishing the answer, learners can immediately see the performance and determine whether they can enter the next level of testing and learning. If the learner's score is less than 85 points, it must be kept in the difficult area for repeated training. The system changes the probability of each question in the question bank according to the students' performance. The probability of the question answered wrongly being extracted is greater and will be extracted again in the next test. In the meanwhile, the same question will not be extracted again if it is done correctly for five times. Again, until the student score is over 85 points, it can enter the next level, as shown in Figure 4. The system will provide students with knowledge points to learn and grasp at the end of each test, so as to solve the problems encountered in the next test. 


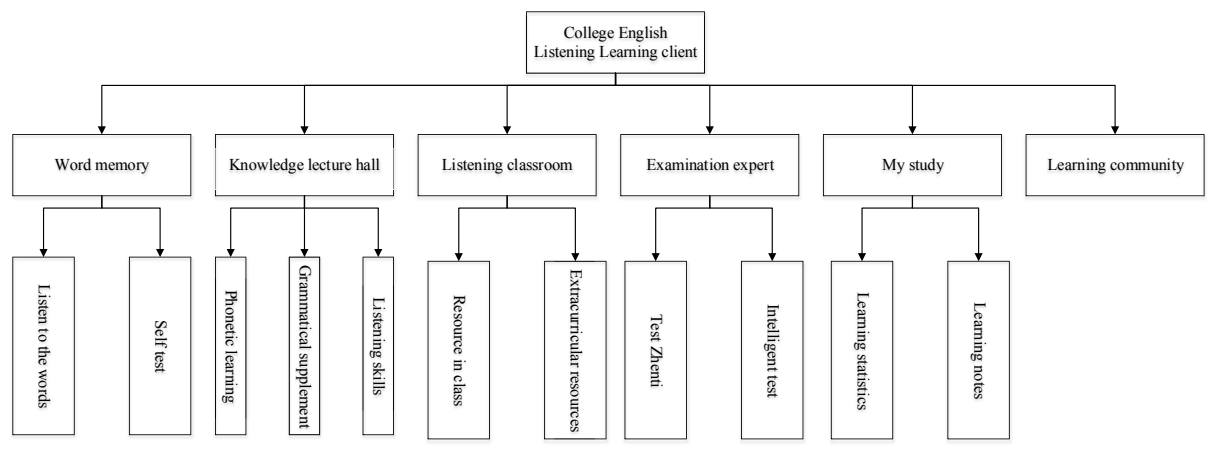

Fig. 4. The Test Procedure

In order to facilitate the operation of the system and meet certain universality, we define the attribute items of each item firstly, so as to facilitate future storage and editing or reading. These attribute items include question number, question difficulty, question option, correct answer, knowledge point, answer correctly times and answer wrongly times. Among them, the question number is the only sign of the test. The question difficulty is the number index to measure the level of question difficulty, which is usually expressed in wrongly answering ratio. The difficulty is generally expressed in letter $\mathrm{P}$. The larger the $\mathrm{P}$ is, the simpler the test question is. The smaller the $\mathrm{P}$ is, the harder it is. There are four options for each test and each question corresponds to the only standard answer. A question can have one or more knowledge points, which is determined by a senior teacher. When the learner does not answer the question correctly, the result of the test feedback will give the corresponding guidance from the knowledge point and help the learners. The number of answering correctly / wrongly: the system is random when the question is extracted firstly. After the learner's answer begins, each question has a record of the number of answering correctly and wrongly. The number of answering correctly is $\mathrm{R}$, the number of answering wrongly is $\mathrm{W}$, and the probability that the question is chosen next time is (1-(R$\mathrm{W}) 5) / \mathrm{N}$. The more the number of answering wrongly is, the greater the probability is and if $\mathrm{R}<\mathrm{W}$, it is recorded as 0 .

The intelligent test question will be subject to the CET-4 and CET-6 level test standard, and the stored questions and extracted question in the question bank are conducted in accordance with three parts: Section A (dialogue), Section B (short passage), and Section $C$ (dictation). The full score is 100 points, and there are a total of 35 questions. There are 8 short conversations, 8 questions, 2 long dialogues, 7 questions, 3 passages, 10 questions, and 1 dictation, 10 questions.

In this paper, the intelligent test module adopts the genetic algorithm to automatically extract and select the topic, which can realize the test paper making with certain difficulty, which greatly improves the effect of the intelligent test.

Because the number of questions and total score of a topic are considered when initializing population, fitness function is mainly restricted by the difficulty of examination paper. Test paper difficulty coefficient formula is shown below: 


$$
\mathbf{P}=\sum \mathrm{Di} \times \mathrm{Si} / \Sigma \mathrm{Si}
$$

In (1), $\mathrm{i}=1,2, \ldots \mathrm{N}, \mathrm{N}$ indicates the number of questions contained in the test paper, and $\mathrm{Di}$ and $\mathrm{Si}$ are the degree of difficulty and the score of the i-th question, respectively. The smaller the difference $f$ between user expectation difficulty coefficient EP and test paper difficulty coefficient $\mathrm{P}$ is, the better it is, $\mathrm{f}=|\mathrm{EP}-\mathrm{P}|$.

In order to make the selected topic finally meet the needs of the user, the intelligent topic selection will be carried out in the following three ways, that is, to determine the genetic operator in the genetic algorithm. Here we use the classic roulette method, that is, to randomly choose two individuals, childl and child2, from the sub generation. Using this function formula (2), we select the individuals with relative high fitness to carry out the next round of evolution. In the selection, the adaptability is the choice principle. The fitness rule reflects the natural law of survival of the fittest and the elimination of those who do not adapt.

$$
\text { fitness }[i]=\frac{f[i]}{\sum_{i=\mathbf{1}}^{\text {sum[i] }} f[i]}
$$

At the time of crossover, the cross section of the single point is used, that is, the crossover is conducted in accordance with the type of questions. Only the subject of the same type will be crossover and changed, so the whole test paper shows a multipoint crossover change. The implementation process of crossover: the subjects of the same type in different test papers are two-two paired, and each set of papers is generated by random number $a$ in $[0,1]$. If $\mathrm{a} \leq \mathrm{pc}$, a cross point is generated randomly, that is, an exchange is carried out, and then the subject is exchanged for the next generation of test papers.

Because the crossover operator can only deal with the topic which has been brought into the test paper, in order to make full use of the resource of the question bank and prevent the shortage of the resource in the initial test paper, it is necessary to change the topic in the generation of the sub test paper. This process is very simple, which is a random generation of a real number $a$ within the range of $[0,1]$. If $\mathrm{a} \leq \mathrm{Pm}$ (it is mutation rate, and pm value is 0.01 to 0.02 ), the question will be suddenly turned into another item in the same score and same question type.

Intelligent analysis is mainly based on the performance of learners, giving learning advice from the system. In previous design, if the learner's score is less than 85 points, then the learner will continue to learn and test; if the score is more than 85 points, it indicates that it has reached the target requirements of this stage, and will be able to enter the next phase of the test.

\subsection{Learning community}

Communication between students is very important and interaction is an important factor in language learning. Learning community can open up the space of external 
communication and learning for students, enhance vision, improve reading and writing output language communication function, and achieve all-round learning.

Limited to the problem of time and ability, the community module is integrated with third party api, and the MOX community's scheme is used. By registering apikey in the MOX community and loading the SDK package and various resource packages of the MOX community, the function of the learning community can be introduced. In this area, the students have arranged four parts of the students' garden, daily English, English making friends and leisure and entertainment, which can be used to exchange or communicate with teachers and students to ensure the maximum output of language and the intake of the latest resources.

\subsection{Application and effect evaluation}

In order to improve the usability and effectiveness of the system, it is necessary to conduct a user feedback survey after the completion of the basic function development. Due to time constraints, part of learning contents are only provided in the trial stage and the main purpose is to get learners' feelings and suggestions about system functions. Through the investigation, it is found that 30 users for Android smart phones, some of them are students who have previously done a questionnaire, and some of them are randomly selected to share the software package by QQ to let the learners download and use them, and to carry out second questionnaires to understand the feelings of the learners and to talk privately to get their advice. This questionnaire mainly involves user's usage, learning effect and evaluation suggestion.

In the use of the system, $49.6 \%$ of the students will often use it, and $36.1 \%$ of the students will sometimes use it. It shows that the mobile English listening learning system developed in this paper has received most of the attention of the students and makes the students feel the convenience of mobile learning in the process of use, as shown in Figure 5.

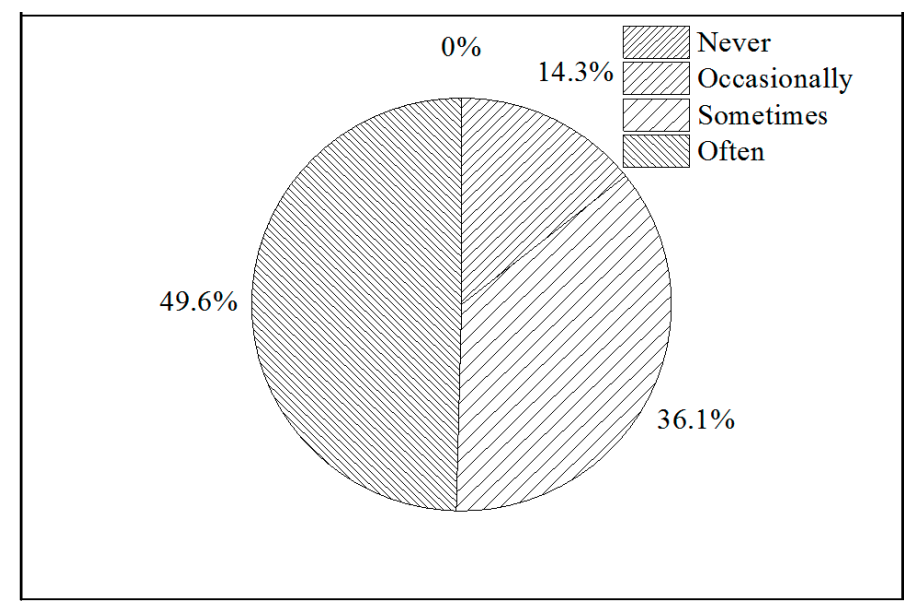

Fig. 5. The Usage of the System 
As for the usefulness of the system, as shown in Figure 6, 27.3\% of the students think that the system is very useful. It is very effective to help them learn their own situation and be pertinent to their needs, especially the intelligent test links; $56.6 \%$ of the students think that it is very useful and suitable for them to help them to tamp the foundation and expand the reading. $16.1 \%$ of the students think that it is commonly. When asked about the reasons, some students reflect that they are more suitable for the traditional way of learning, not very accustomed to the way of movement; some students think that their own self-control is not enough, and it is difficult to concentrate on the mobile listening learning; and some students show that there is no difference from their original study.

On the problem of system usability, as shown in Figure 7, 22.9\% of the students think it is very good. They show that the system function is clear, the structure is simple and clear, and it is the way they need to learn; $61.8 \%$ of the students think the system is very good, not only convenient and fast, but also with very strong content applicability; $13.2 \%$ of the students believe that it is commonly because its operation is almost the same with other software on mobile phones; $2.1 \%$ of the students think that the system is not good enough to use and they more accept traditional way.

In the survey of system function perfection, as shown in Figure 8, 21.4\% of the students think that it is very perfect and can support them to further consolidate and improve; $53.5 \%$ of the students think that it is perfect and basically include the knowledge and function they need; the remaining $25.1 \%$ students have other requirements for the system. For example, some students expect that the test questions should be richer; some students hope to have a special entertainment module; some students feel that the system is lack of voice function and cannot combine the spoken language. As for the requirement of test questions richness, we can increase test subjects such as postgraduate entrance examination and overseas English in the later stage, so as to enrich test contents. Due to the limitation of personal ability, it is necessary to study the function of entertainment module and voice for a long time to improve the function of the system.

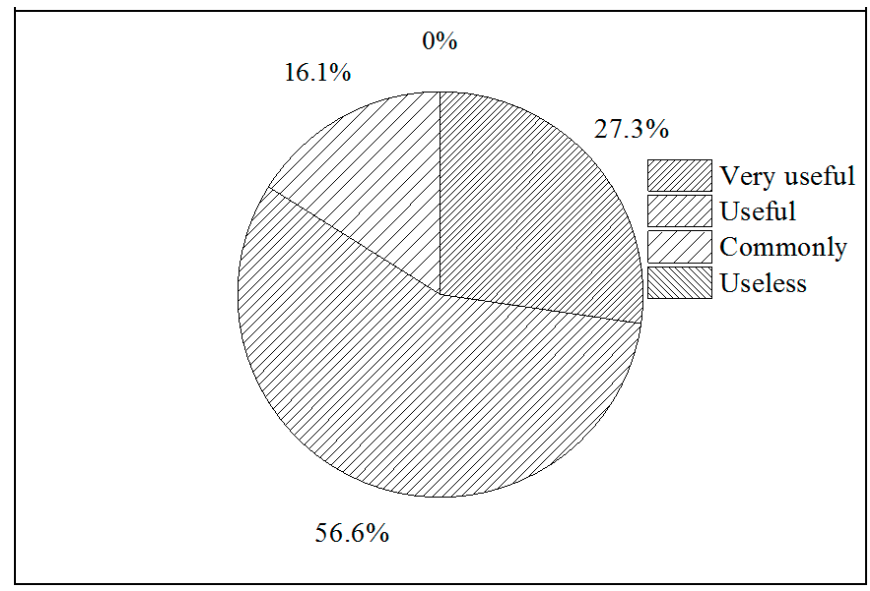

Fig. 6. The Survey of Usefulness about System 


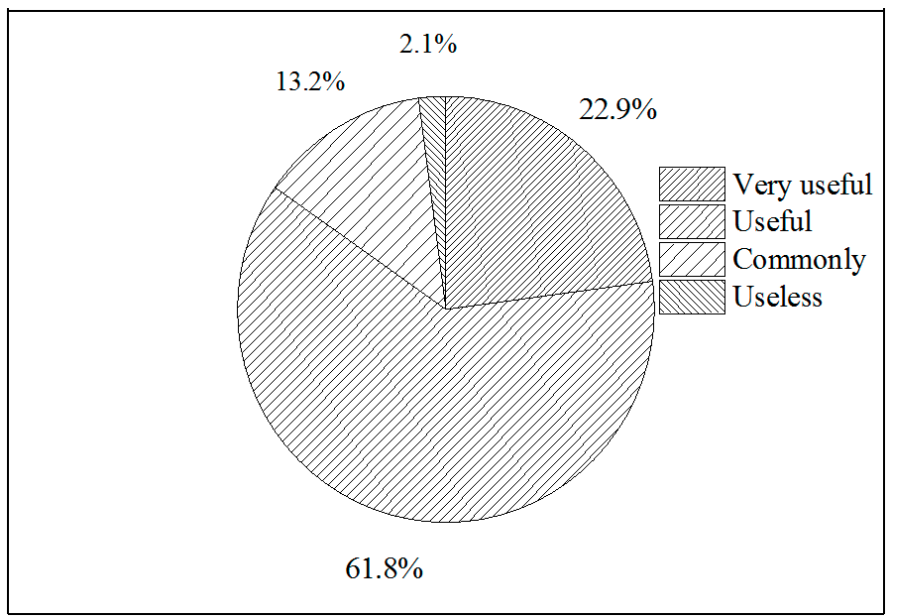

Fig. 7. The Survey of Ease of Use about System

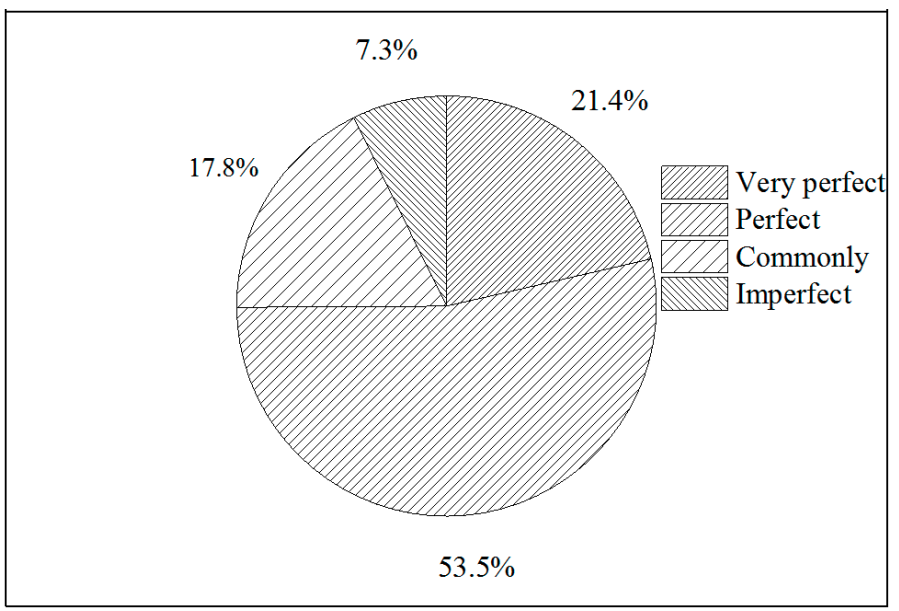

Fig. 8. The Survey of Functions about System

When it comes to the problem of improving the level of listening, as shown in Figure $9,30.5 \%$ of the students think that their listening level is improved very much. They can review and strengthen their memory at any time by system, while they can also understand their own situation according to the intelligence test, and have the targeted learning; $33.9 \%$ of the students think that the listening level is improved a lot. Their fear about English listening is changed into acceptance so that they like to learn; $18.5 \%$ of the students think that it is commonly and the reason is that they rarely use the system so that it is difficult to tell the practical effect of the system; $17.1 \%$ of the students think that their listening level is not improved, and this is closely related to the personal situation and listening training. It also indicates that the system needs for great improvement. 
As for the evaluation of the system, as shown in Figure 10, 22.4\% of the students think that it is very good, and it is both convenient and fashionable, and can also bring them more practical evaluation functions, so they like it very much; $53.5 \%$ of the students think that it is good, and the advantages of mobile learning solve the things that they need hesitation or not to do immediately. At the same time, the system conforms to their learning status, knowing what they want, and more pertinent; $18.7 \%$ of the students think that the reason is that they rarely use the system so that it is difficult to tell the practical effect of the system; $5.4 \%$ of the students think that the system is not good and they accept traditional ways more.

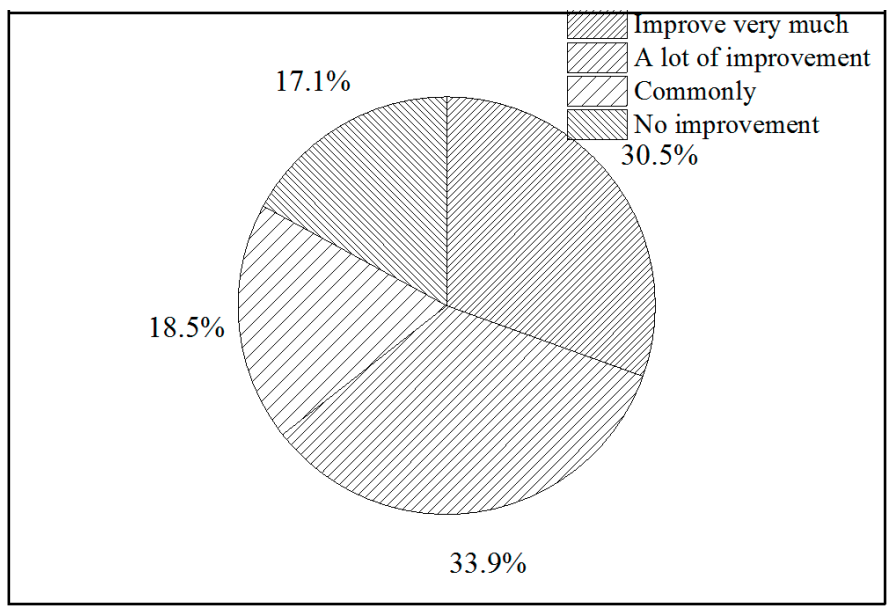

Fig. 9. The Survey of Improving Listening Level about System

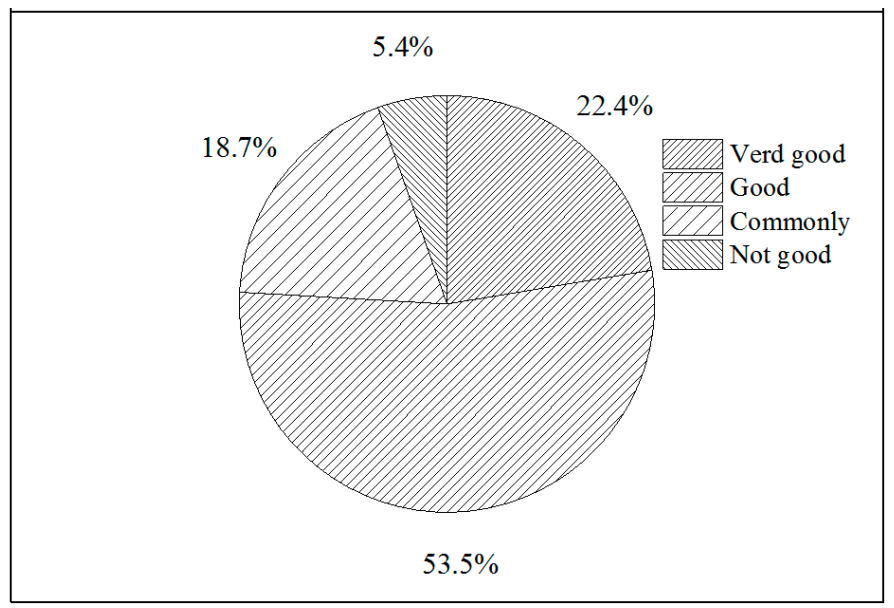

Fig. 10.The Survey Of Evaluation About System 


\section{Conclusion}

Based on the current popular Android software, this paper analyzes the needs of mobile English listening learning, designs the main functional modules of the system, and gives the main steps to realize the system. Finally, the system is tested and the user feedback is obtained. The college English listening learning system designed in this paper increases the intelligence test, strengthens the listening training and feedback mechanism, and helps to improve the listening level step by step. In order to get a good application, mobile learning resources should pay attention to providing a happy learning experience for the learners, build the learner as the center, take the learning needs as the guidance, and promote it with technology. In the later stage, the entertainment and leisure modules will be added to supplement interesting atmosphere to the system.

\section{$6 \quad$ References}

[1] Chappel, R., \& Paliwal, K. (2014). An educational platform to demonstrate speech processing techniques on Android based smart phones and tablets. Elsevier Science Publishers B. V. 57 (2),pp. 13-38

[2] Zheng, Z., Cheng, J., \& Peng, J. (2015). Design and implementation of teaching system for mobile cross-platform. International Journal of Multimedia \& Ubiquitous Engineering, 10(2), pp. 287-296. https://doi.org/10.14257/ijmue.2015.10.2.26

[3] Zhang, B. (2017). Research on framework design of english mobile teaching system in higher vocational colleges based on android platform. Boletin Tecnico/technical Bulletin, 55(15), pp. 174-181.

[4] Tong, J. (2016). Design and implementation of music teaching platform in college based on android mobile technology. International Journal of Emerging Technologies in Learning, 11(5), pp. 4. https://doi.org/10.3991/ijet.v11i05.5686

[5] Dewitt, D., Alias, N., \& Siraj, S. (2014). The design and development of a collaborative mlearning prototype for malaysian secondary school science. Educational Technology Research \& Development, 62(4), pp. 461-480. https://doi.org/10.1007/s11423-014-9340-y

[6] Liao, C., Lin, P., Du, J., \& Li, Z. (2014). Design and implementation of pharmacopoeia smart learning system based on android platform. , 91(7), pp. 225-228. https://doi.org/10.2991/iceeim-14.2014.66

[7] Ally, M., \& Prietoblázquez, J. (2014). What is the future of mobile learning in education?. International Journal of Educational Technology in Higher Education, 11(1),pp. 142-151.

\section{Author}

Hongbo Huang is with University of Science and Technology Liaoning, Liaoning Province 114044, China.

Article submitted 25 April 2018. Final acceptance 07 May 2018. Final version published as submitted by the author. 